ISSN 0103-9954

\title{
DETERMINAÇÃO DO TEOR DE SÍLICA EM MADEIRA POR ESPECTROSCOPIA DE ABSORÇÃO ATÔMICA DE CHAMA VERSUS ESPECTROSCOPIA NO ULTRAVIOLETA- VISÍVEL
}

\author{
DETERMINATION OF SILICA CONTENT IN WOOD BY FLAME ATOMIC ABSORPTION \\ SPECTROSCOPY VERSUS ULTRAVIOLET-VISIBLE SPECTROSCOPY
}

\author{
Laécio Carneiro Rodrigues ${ }^{1}$ Marcos Antonio Eduardo Santana ${ }^{2}$
}

\section{RESUMO}

O presente trabalho teve como objetivo comparar o desempenho de duas técnicas analíticas, espectroscopia de absorção atômica de chama (FAAS) e espectroscopia no ultravioleta-visível (UV-VIS), na determinação do teor de sílica em materiais lignocelulósicos. Os métodos foram testados em amostras de madeira de três árvores de Apuleia leiocarpa (Vog.) Macbride. Os resultados mostraram que ambas as técnicas apresentam bons resultados, no entanto, a FAAS apresenta melhor precisão, rapidez e simplicidade operacional. Entretanto, a aplicação da espectroscopia UV-VIS é justificada pelo fato de os custos de aquisição e manutenção de um espectrofotômetro UV-VIS serem muito inferiores àqueles de um espectrômetro de absorção atômica. O uso da técnica FAAS deve ser preferido apenas quando os teores de sílica a serem determinados forem muito baixos, tendo em vista que a espectroscopia UV-VIS, nesses casos, não apresenta boa precisão.

Palavras-chave: madeiras tropicais; materiais inorgânicos; silicatos e silício.

\section{ABSTRACT}

The objective of this work was to compare the performance of two analytical techniques, flame atomic absorption spectroscopy (FAAS) and ultraviolet-visible spectroscopy (UV-VIS), in the determination of the silica content in lignocellulosic materials. The methods were tested in wood specimens of three trees of Apuleia leiocarpa (Vog.) Macbride. The results showed that both techniques present good performance, but the FAAS presents better precision, speed and operational simplicity. However, the application of the UV-VIS spectroscopy is justified by the fact of the acquisition and maintenance costs of an UV-VIS spectrophotometer are lower when compared to those of a spectrometer of atomic absorption. The use of the FAAS technique should just be chosen when the silica content is expected to be very low, once the UV-VIS spectroscopy, in those cases, does not present good precision.

Keywords: tropical woods; silicon; silicates and inorganic materials.

\section{INTRODUÇÃO}

A análise química é muito importante no estudo da qualidade da madeira, uma vez que algumas propriedades físicas e mecânicas têm relação estreita com sua morfologia e composição química (TRUGILHO et al., 1977).

Os componentes minerais da parede celular das plantas incluem silício, presente predominantemente na forma de sílica, mas também estruturalmente ligado aos carboidratos e a outros elementos, tais como cátions metálicos, os quais geralmente estão ligados ou complexados pela lignina, carboidratos e sílica (JONES, 1978).

As plantas que contêm elevado teor de Si são menos suscetíveis ao ataque de pragas, tais como fungos e insetos, e, além disso, possuem maior rigidez estrutural (JONES, 1978; XIA et al., 2000). Por outro lado, espécies de madeiras com alto teor de Si são menos suscetíveis ao ataque de organismos marinhos (PANSHIN e DE ZEEUW, 1980).

A sílica é comumente encontrada em várias famílias de madeiras tropicais e menos freqüente em madeiras de zonas temperadas. Vasconcelos et al. (1995) investigaram a distribuição de minerais, cristais e sílica, no xilema secundário de 250 espécies, representando 53 famílias de madeiras da Amazônia. A

1. Bacharel em Química, Laboratório de Produtos Florestais (LPF), Instituto Brasileiro do Meio Ambiente (IBAMA), SCEN Trecho 02, CEP 70818-900, Brasília, (DF). laeciocarneiro@yahoo.com.br

2. Químico, PhD., Analista Ambiental, Pesquisador do Laboratório de Produtos Florestais (LPF), Instituto Brasileiro do Meio Ambiente (IBAMA), SCEN Trecho 02, CEP 70818-900, Brasília (DF). marcos.santana@ibama.gov.br

Recebido para publicação em 10/11/2006 e aceito em 18/05/2007. 
presença de sílica ocorre em aproximadamente 36\% das espécies estudadas.

A sílica ocorre nas células procumbentes, na forma de corpos arredondados e amorfos, os quais aumentam de tamanho no sentido do alburno para o cerne (Panshin e de Zeeuw, 1980). De acordo com Jones (1978), as espécies de folhosas (angiospermas) contêm de 0,1 a 0,4\% de sílica. Entretanto, um grupo de espécies dos gêneros Licania e Parinari e várias espécies do gênero Eschweilera possuem mais de 2\% de sílica (PANSHIN e de ZEEUW, 1980).

Sabe-se, no entanto, que a sílica se distribui de maneira não-uniforme nas diferentes partes das plantas. Por isso, empregando-se a microscopia eletrônica, esforços têm sido feitos com o objetivo de se conhecer melhor as estruturas, bem como as localizações, dos corpos silicosos nos tecidos das plantas (JONES, 1978).

O conhecimento prévio do teor de sílica existente em tais espécies é, sem dúvida, muito útil ao desenvolvimento de melhores estratégias de processamento industrial da madeira. Além disso, elevados teores de sílica na madeira têm se revelado indicativos de maior resistência a organismos marinhos.

Os métodos mais comumente utilizados para determinação do teor de sílica em espécies de madeira são as análises gravimétricas (TAPPI 1996a; HORWITZ, 1960; VOLK e WEINTRAUB, 1958). Tais métodos se encontram desatualizados, além de serem demorados, cansativos e imprecisos. As análises nas quais se empregam esses métodos geralmente são feitas tratando-se as cinzas das amostras com ácidos minerais e com sucessivos e longos aquecimentos. Além disso, os referidos métodos não possuem bons limites de detecção.

Novozamsky et al. (1984) verificaram que os silicatos contidos em materiais secos provenientes de plantas podem ser extraídos quantitativamente, à temperatura ambiente, usando-se uma mistura de ácido fluorídrico e ácido clorídrico diluídos. O silício contido nesse extrato pode ser determinado tanto por espectroscopia de absorção atômica de chama (FAAS), como por espectroscopia de emissão atômica por plasma indutivamente acoplado (ICP- AES).

Van Der Vorm (1987) analisou as mesmas matrizes estudadas por Novozamsky et al.(1984) via espectrofotometria UV-VIS. A análise foi feita depois de as amostras terem sido submetidas a um tratamento de secagem, transformadas em cinzas e digeridas com ácido fluorídrico e ácido sulfúrico.

Xia et al. (2000) utilizaram uma adaptação do método de Van Der Vorm (1987) para determinar o teor de sílica em ervas, cosméticos e produtos farmacêuticos por espectrofotometria.

Rodrigues e Santana (2005) apresentaram um método para determinação do teor de sílica em materiais lignocelulósicos por espectroscopia no ultravioleta-visível e verificaram a sua aplicabilidade e reprodutibilidade na determinação do teor de sílica na madeira de Couratari stellata A.C.Sm. Os resultados obtidos permitiram concluir que o método proposto fornece resultados reprodutíveis, confiáveis e de fácil execução.

O objetivo do presente trabalho é comparar o desempenho de duas técnicas analíticas, espectroscopia no ultravioleta-visível (UV-VIS) e espectroscopia de absorção atômica de chama (FAAS), na determinação do teor de sílica em materiais lignocelulósicos.

\section{MATERIAL E MÉTODOS}

Neste trabalho, foram comparados os resultados obtidos para os teores de sílica para amostras de madeira de três árvores de Apuleia leiocarpa (Vog.) Macbride, fazendo-se uso de duas técnicas analíticas: a espectroscopia UV-VIS, segundo o método proposto por Rodrigues e Santana (2005), e a espectroscopia de absorção atômica de chama, pelo método proposto por Novozamsky et al. (1984). Ressalta-se, no entanto, que, na intenção de possibilitar a análise das mesmas alíquotas de amostras por ambas as técnicas e no mesmo dia, foi necessário que se fizessem pequenas adaptações em ambos os métodos. Essas modificações, como observado em testes preliminares, não prejudicaram o desempenho dos referidos métodos. Por motivo de clareza, tais modificações apenas serão explicitadas à medida que os métodos forem sendo descritos.

Três árvores de Apuleia leiocarpa foram coletadas na Floresta Nacional do Tapajós, localizada no município de Santarém, estado do Pará. A coleta foi realizada em conformidade com o "Sistema de Amostragem Direta ao Acaso" (BENDTSEN et al., 1970; NOACK, 1970), fazendo-se as adaptações 
necessárias impostas pelas condições peculiares à região amazônica. Da base do tronco de cada uma das árvores, foi retirado um disco, que foi dividido em quatro partes. Em seguida, um quarto de cada um desses discos foi transformado em palitos, os quais foram moídos em um moinho tipo Willey, e a granulometria de interesse foi obtida fazendo-se a separação das partículas em um sistema de peneiras. A fração de madeira que passou pela peneira de 35 mesh (abertura de $420 \mu \mathrm{m}$ ) e que ficou retida na peneira de 60 mesh (abertura de $250 \mu \mathrm{m}$ ) foi utilizada para as determinações do teor de sílica.

A preparação das amostras livres de extrativos foi realizada de acordo com a norma TAPPI T 264 om-82 (TAPPI, 1996b), e a secagem do material foi feita em estufa a $105 \pm 2{ }^{\circ} \mathrm{C}$.

Em frascos de polipropileno de $125 \mathrm{~mL}$, foram pesadas, em triplicata, alíquotas de aproximadamente 1500 mg da madeira moída seca e livre de extrativos, provenientes de cada uma das três árvores.

Nessa etapa do procedimento, introduziu-se uma modificação no método de Novozamsky et al. (1984), pois, enquanto eles sugerem a pesagem e a digestão de $300 \mathrm{mg}$ de amostra, neste trabalho, fez-se necessário pesar e digerir $1.500 \mathrm{mg}$ de amostra, tendo em vista que parte dos extratos obtidos com essa digestão foi usada na análise espectrométrica por UV-VIS, método no qual se trabalha com pesagens de 1500 mg (Rodrigues e Santana, 2005). Essa alteração do procedimento foi realizada para evitar que a complexa e aleatória distribuição dos corpos silicosos nos tecidos das árvores influenciasse na determinação do teor de sílica, uma vez que, dificilmente, obter-se-á resultados de teores de sílica idênticos para análises de alíquotas diferentes mesmo se provenientes de um mesmo indivíduo. Observa-se, então, que, na análise via absorção atômica, trabalhou-se com extratos mais concentrados.

A cada uma dessas alíquotas, pesadas na etapa anterior, foram adicionados $20 \mathrm{~mL}$ de ácido fluorídrico 2,3 mol/L e $10 \mathrm{~mL}$ de ácido clorídrico $1 \mathrm{~mol} / \mathrm{L}$, e as misturas resultantes foram agitadas por 14 horas. Em seguida, os extratos obtidos foram filtrados, usando-se funil de polipropileno e papel filtro.

Para a posterior análise em UV-VIS, separou-se $10 \mathrm{~mL}$ do extrato filtrado, com auxílio de uma pipeta de polipropileno. A alíquota restante desse extrato foi submetida à análise por absorção atômica de chama.

\section{Determinação do teor de $\mathrm{SiO}_{2}$ por espectroscopia de absorção atômica}

Para a obtenção da curva analítica, preparou-se uma série de soluções, diluindo-se alíquotas de uma solução padrão de 1.000 ppm de Si, o que possibilitou obter padrões com as seguintes concentrações: 0, 25, 50, 100 e 200 ppm.

As leituras desses padrões e as determinações dos teores de $\mathrm{Si}$ dos extratos foram feitas a 251,6 nm em um espectrômetro de absorção atômica Varian modelo SpectraAA-110, usando-se chama de óxido nitroso/acetileno fortemente redutora.

\section{Determinação do teor de sílica por UV-VIS}

As alíquotas de $10 \mathrm{~mL}$ dos extratos, anteriormente separadas para a análise por espectroscopia no UV-VIS, foram diluídas para $50 \mathrm{~mL}$ com ácido sulfúrico $0,08 \mathrm{~mol} / \mathrm{L}$ e novamente agitadas por mais 10 minutos.

Originalmente, o método proposto por Rodrigues e Santana (2005), $40 \mathrm{~mL}$ de extrato, obtidos da digestão de $1500 \mathrm{mg}$ de amostra em $20 \mathrm{~mL}$ de $\mathrm{HF}$ 2,3 mol/L e de 20 de $\mathrm{HCl} 1 \mathrm{~mol} / \mathrm{L}$, são diluídos para $100 \mathrm{~mL}$ com $\mathrm{H}_{2} \mathrm{SO}_{4}$ 0,08 mol/L. Logo, a diluição de $10 \mathrm{~mL}$ de extrato para $50 \mathrm{~mL}$, com $\mathrm{H}_{2} \mathrm{SO}_{4}$ 0,08 mol/L, gera soluções mais diluídas que aquelas obtidas pela diluição proposta no método original desses autores. Essa diluição adicional não prejudica o desempenho do método, como foi verificado em testes preliminares.

Desse ponto em diante, para a determinação do teor de sílica por espectroscopia no UV-VIS, foi utilizado o método proposto por Rodrigues e Santana (2005) sem nenhuma outra alteração. As leituras das amostras e dos padrões da curva de calibração foram realizadas em um espectrofotômetro FEMTO modelo 700 Plus.

\section{RESULTADOS E DISCUSSÃO}

A madeira de Apuleia leiocarpa (Vog.) Macbride, conhecida popularmente por garapa, grápia ou garapeira, foi selecionada para o presente estudo, pois as análises qualitativas por microscopia ótica, 
realizadas na Área de Anatomia e Morfologia do Laboratório de Produtos Florestais - LPF/IBAMA, indicaram a presença de sílica no parênquima axial, como pode ser visto na Figura 1.

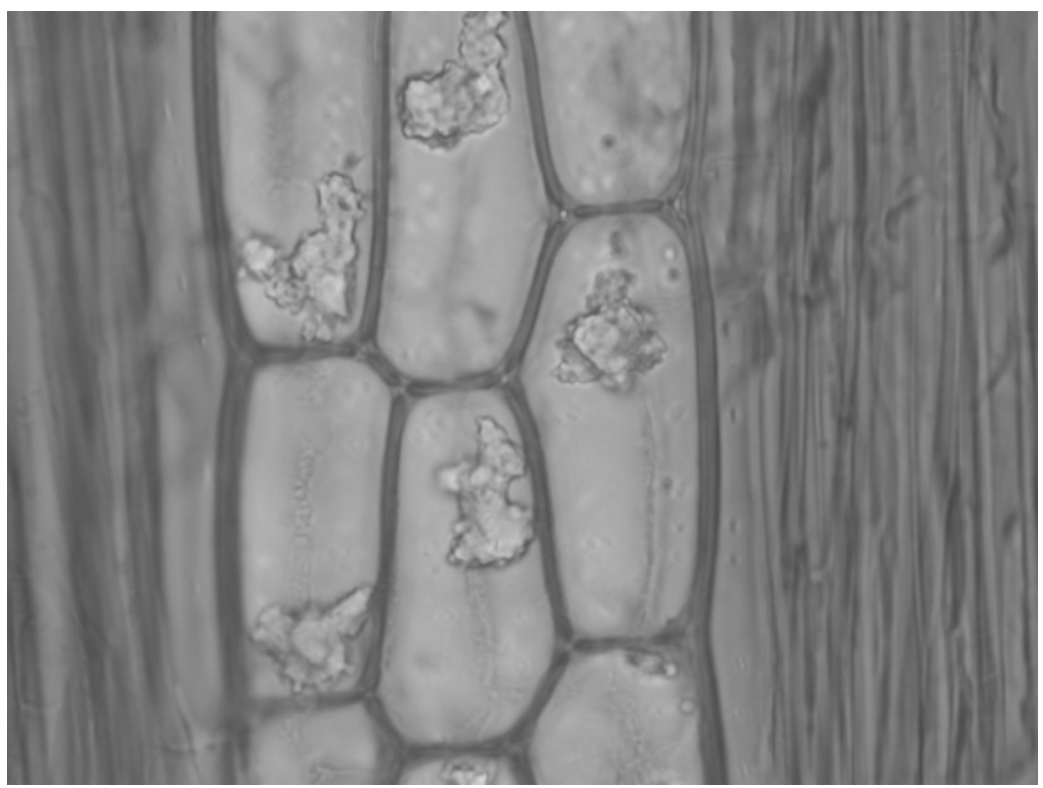

FIGURA 1: Foto micrografia ilustrando a presença de sílica em Apuleia leiocarpa. As setas indicam a localização dos corpos silicosos amorfos em células de parênquima axial.

FIGURE 1: Micrograph illustrating the presence of silica in Apuleia leiocarpa wood. The arrows indicate the location of amorphous bodies of silica in axial parenchyma.

Os teores médios de sílica encontrados em cada uma das três árvores de Apuleia leiocarpa, conforme o procedimento adequado a cada uma das duas técnicas, estão resumidos na Tabela 1.

TABELA 1: Teor médio de sílica para três árvores de Apuleia leiocarpa para os dois métodos testados e seus respectivos coeficientes de variação.

TABLE 1: Average values of silica content for three specimens of Apuleia leiocarpa for the two tested methods and their respective coefficients of variation.

\begin{tabular}{c|c|c}
\hline \multirow{2}{*}{ Código da Árvore } & \multicolumn{2}{|c}{ Teor de Sílica (\%) } \\
\cline { 2 - 3 } & $\mathrm{UV}-V I S^{\mathrm{a}}$ & FAAS $^{\mathrm{a}}$ \\
\hline 1 & 1,16 & 1,52 \\
& $(3,10)^{\mathrm{b}}$ & $(2,37)^{\mathrm{b}}$ \\
\hline 2 & 1,72 & 1,98 \\
& $(2,84)^{\mathrm{b}}$ & $(2,22)^{\mathrm{b}}$ \\
\hline 3 & 0,38 & 0,45 \\
& $(19,29)^{\mathrm{b}}$ & $(1,99)^{\mathrm{b}}$ \\
\hline
\end{tabular}

Em que: a = Média de três análises; $b$ = Coeficiente de variação para as três medidas.

Ao se comparar os resultados apresentados na Tabela 1, verifica-se que, para cada uma das três árvores estudadas, os teores médios de sílica obtidos via FAAS são sempre maiores que aqueles obtidos via espectroscopia UV-VIS. Tendo em vista tratar-se de métodos muito distintos, tais diferenças são razoáveis, podendo ser explicadas pelos fatores a seguir:

a) Na espectroscopia UV-VIS, há a necessidade de modificar o analito (Si) quimicamente para que ele seja detectado pelo instrumento. Essa modificação química, chamada derivatização, ocorre na etapa em que o Si reage com o heptamolibdato de amônio, para que haja a formação de cor. Além disso, enquanto na espectrofotometria UV-VIS o analito é detectado na forma molecular, em solução; na FAAS, o analito é detectado na forma de átomos, no estado gasoso.

b) Para o elemento Si, o limite de detecção da técnica de FAAS é melhor que o da espectroscopia UV-VIS, pois, apesar de as amostras analisadas terem sido as mesmas, por ambas as técnicas, os teores de sílica obtidos por FAAS são sempre maiores que aqueles obtidos por espectroscopia UV-VIS. 
Esses são os principais fatores que impedem a obtenção de teores de sílica "idênticos” por ambas as técnicas. Em contrapartida, as diferenças entre os teores de sílica para as três árvores, independente da técnica empregada, pode ser explicada pelo fato de a quantidade de ácido silício absorvida pelo vegetal variar conforme clima, idade da planta e tipo de solo.

A reprodutibilidade, isto é, a precisão dos dados obtidos por FAAS é sempre melhor que aquela associada às medidas feitas por espectroscopia UV-VIS. Isso é constatado quando se compara o coeficiente de variação calculado para as medidas realizadas. Para a árvore 3, por exemplo, o coeficiente de variação calculado para as análises por absorção atômica é quase dez vezes menor que o coeficiente de variação calculado para as análises via espectroscopia UV-VIS. Isso comprova que, com a FAAS, tem melhor precisão. É interessante notar, no entanto, que a precisão do método para espectroscopia UV-VIS só se torna comprometida quando se analisa amostras que contêm teores muito baixos de sílica, como é o caso da árvore 3. Mesmo assim, continua-se considerando esse método espectrométrico muito útil para essa finalidade, pelo fato de a sua relação custo-benefício ser bastante compensadora.

Outro aspecto importante que pode ser observado nos dados da Tabela 1 é que, para ambas as técnicas, a precisão dos resultados obtidos melhora com o aumento do teor de sílica, pois os coeficientes de variação diminuem quando o teor de sílica aumenta. Isso sugere que, quanto maior o teor de sílica do indivíduo em estudo, mais confiáveis e menos dispersos serão os resultados obtidos. Como exemplo, pode-se verificar que, quando o teor de sílica é elevado, como é o caso das árvores 1 e 2, a precisão de ambos as métodos, para ambas as técnicas, torna-se semelhante.

A FAAS, além de oferecer melhor reprodutibilidade e limite de detecção que a espectroscopia UV-VIS, tem importantes vantagens operacionais, pois demanda menos tempo e trabalho. Com a FAAS, os extratos provenientes das digestões das amostras são prontamente analisados, enquanto que, para as análises por espectroscopia UV-VIS, são necessárias diversas etapas posteriores à digestão.

A grande vantagem da espectroscopia UV-VIS, nesse caso, é o custo da instrumentação e da manutenção, que são muito inferiores aos da FAAS.

\section{CONCLUSÕES}

Tanto a espectroscopia no ultravioleta visível como a espectroscopia de absorção atômica de chama apresentam bom desempenho, quando aplicadas à determinação dos teores de sílica de espécies vegetais, apesar de a última dessas técnicas proporcionar melhor precisão, rapidez e simplicidade operacional. A aplicação da espectroscopia UV-VIS, no entanto, justifica-se pelo fato de os custos de aquisição e manutenção de um espectrofotômetro UV-VIS serem muito inferiores aos de um espectrômetro de absorção atômica. O uso da técnica FAAS deve ser preferido apenas quando os teores de sílica a serem determinados forem muito baixos, tendo em vista que a espectroscopia UV-VIS, nesses casos, não apresenta boa precisão.

O uso de ambos os métodos testados é de grande valor para a indústria madeireira, pois o conhecimento prévio do teor de sílica possibilita o processamento das madeiras de forma estratégica, contribuindo para a redução dos custos de produção.

\section{REFERÊNCIAS BIBLIOGRÁFICAS}

BENDTSEN, B.A.; FREESE, F.; ETHINGTON, R.L.A. A forest sampling method for wood strength. Forest Products Journal, Madison, v.20, n. 11, p. 49-53, 1970.

HORWITZ, W. Official methods of analysis of the association of official agricultural chemists. 4. ed. Washington: Association of Analytical Chemistry, 1960. 73p.

JONES, L.P.H. Mineral components of plant cell walls. The American Journal of Clinical nutrition, New York, v.31, p.s94-s97, 1978.

NOACK, D. Evaluation of properties of tropical timber. Hamburgo: IUFRO, 1970.

NOVOZAMSKY, I.; VAN ECK, R.; HOUBA, V.J.G. A rapid determination of silicon in plant material. In Communication in soil science and plant analysis, New York, v.15, n.3, p. 205-211, 1984.

PANSHIN, A.J.; DE ZEEUW, C. Textbook of Wood Technology: Structure, identification, properties and uses of the commercial woods of the United States and Canada. New York: McGraw-Hill Book Company, 1980. 772 p.

RODRIGUES, L. C.; SANTANA, M. A. E. Metodologia para determinação do teor de sílica em materiais 
lignocelulósicos via espectrometria no ultravioleta-visível. Floresta \& Ambiente, Rio de Janeiro, v.12, n.1, p. 57-62, 2005.

TAPPI. Ash in wood, pulp, paper and paperboard: combustion at $525^{\circ} \mathrm{C} . \mathrm{T}-211$ om-93. TAPPI test methods. Atlanta: TAPPI Press, 1996a.

TAPPI. Preparation of wood for chemical analysis. T-264 om-88. TAPPI test methods. Atlanta: TAPPI Press, 1996b.

TRUGILHO, P.F., MENDES, L.M., SILVA, J.R.M., LIMA, J.T. Influência da idade nas características físicas, químicas e anatômicas da madeira de Eucalyptus grandis. In: IUFRO CONFERENCE ON SOIL SILVICULTURE AND IMPROVEMENT OF EUCALYPTUS. 1977, Salvador. Anais... Colombo: EMBRAPA - Centro Nacional de Pesquisa de Florestas, 1977. v. 4. p. 269-275.

VAN DER VORM, P.D.J. Dry ashing of plant material and dissolution of the ash in HF for the colorimetric determination of silicon. Communication in soil science and plant analysis, New York, v.18, n.11, p.1181-1189, 1987.

VASCONCELOS, F.J. de, FREITAS. J.A. de, SILVA, A.C. Observação microscópica de inclusões minerais no xilema de espécies tropicais da amazônia. Acta Amazônica, Manaus, v.25, n.1/2, p. 55-68, 1995.

VOLK, R.J. \& WEINTRAUB, R.J. Microdetermination of silicon in plants. Analytica Chimica Acta, Amsterdam, v. 30, p. 1011-1014, 1958.

XIA, X.; BELAND, R.; MIERSCH, S.; HOUDE, D.; ABOUL-ENEIN, H.Y. Development and validation method for silica determination by spectrophotometry in some herbs and pharmaceutical formulations. Analytical Letters, New York, v. 33, n.3, p. 455-463, 2000. 